\title{
Permasalahan guru IPS dalam pengembangan media pembelajaran di SMP Brawijaya Smart School Malang berbasis TIK
}

\author{
Muhammad Khoiro, I Nyoman Ruja*, Sukamto, Siti Malikhah Towaf \\ Universitas Negeri Malang, Jl. Semarang No. 5 Malang, Jawa Timur, Indonesia \\ *Penulis korespondensi, Surel: nyoman.ruja.fis@um.ac.id
}

Paper received: 02-03-2021; revised: 15-03-2021; accepted: 30-03-2021

\begin{abstract}
Learning today can be facilitated with the help of technology that can be utilized by teachers in presenting learning materials in the teaching and learning process. In order to facilitate teachers in carrying out the teaching and learning process can use the main learning media based on Information and Communication Technology (ICT). But the phenomenon that occurs, teachers experience a lot of problems when developing ICT-based learning media. Qualitative research method of phenomenological approach can be understood that the results of research in SMP BSS show; 1) The awareness of IPS teachers in SMP BSS the importance of ICT-based learning media; 2) Teacher problems in developing ICT-based learning media in the form of, how to operate media software and follow the development of technology; 3) factors of problematika emergence, namely, age factors, lack of skills mentoring, differences learned between generations, overload of additional tasks, and lack of opportunities in the division of time to learn; 4) addressing the problems that arise, ips teachers at SMP BSS take a stand by doing time management, and also the spirit of continuing to learn ICT-based learning media; 5) the hope of ips teachers in SMP BSS is that there is a paya fulfillment of facilities from the agency so that the problems they face can be resolved.
\end{abstract}

Keywords: problematics; teachers; social studies; media; ICT

\begin{abstract}
Abstrak
Pembelajaran saat ini dapat dipermudah dengan bantuan teknologi yang bisa dimanfaatkan oleh guru dalam menyajikan materi pembelajaran dalam proses belajar mengajar. Guna mempernudah guru dalam melaksanakan proses belajar mengajar dapat menggunakan media pembelajaran utamanya berbasis Teknologi Informasi dan Komunikasi (TIK). Namun fenomena yang terjadi, guru banyak mengalami problematika ketika mengembangkan media pembelajaran berbasis TIK. Metode penelitian kualitatif pendekatan fenomenologi dapat dipahami bahwa hasil penelitian di SMP BSS menunjukkan; 1) Adanya kesadaran guru IPS di SMP BSS pentingnya media pembelajaran berbasis TIK; 2) Permasalahan guru dalam mengembangkan media pembelajaran berbasis TIK berupa, cara pengoperasian software media dan mengikuti perkembangan teknology; 3) factor munculnya problematika yakni, factor usia, tidak adanya pendampingan keterampilan, perbedaan yang dipelajari antar generasi, overload tugas tambahan, dan kurangnya kesempatan dalam pembagian waktu untuk belajar; 4) menyikapi problematika yang muncul, guru IPS di SMP BSS mengambil sikap dengan melakukan manajemen waktu, dan juga semangat terus belajar media pembelajaran berbasis TIK; 5) harapan guru IPS di SMP BSS yakni ada paya pemenuhan fasilitas dari instansi agar problematika yang mereka hadapi dapat teratasi.
\end{abstract}

Kata kunci: problematika; guru; IPS; media; TIK

\section{Pendahuluan}

Teknologi dapat dikatakan terus berkembang dalam berbagai sektor, salah satunya dalam sektor pendidikan. Sebagai salah satu upaya agar pendidikan di Indonesia tetap bisa mengikuti perkembangan teknologi, pemerintah mengeluarkan dua peraturan yang terkait 
dengan pendidikan di Indonesia. Tertulis dalam (Peraturan Menteri Pendidikan Nasional No. 16 Tahun 2007 tentang Standar Kualifikasi Akademik dan Kompetensi Guru. Menteri Pendidikan Nasional) bahwa guru harus dapat memanfaatkan TIK untuk menunjang pembelajaran. Selain itu guru juga harus memanfaatkan TIK untuk komunikasi dan pengembangan keterampilan diri.

Berdasarkan dari PERMENDIKNAS Nomor 16 tahun 2007 maupun PPRI nomor 74 tahun 2008, dapat dilihat bahwa pemerintah merencanakan agar pendidikan yang ada di Indonesia dapat berkembang secara dinamis mengikuti perkembangan teknologi. Agar hal tersebut dapat terlaksana dengan baik, tentunya diperlukan kerja sama dengan berbagai pihak. Namun, pihak yang menjadi ujung tombak adalah guru, karena guru merupakan pihak yang langsung berhadapan dengan peserta didik.

Seorang guru harus mampu menjadikan kegiatan belajar menjadi bermakna. (Majid, 2014) menjelaskan "kebermaknaan dalam belajar atas hasil dari kegiatan mengajar ditandai dengan terjadinya korelasi antara aspek yang dipelajari, konsep, situasi baru dengan komponen yang relevan di dalam struktur kognitif siswa. Supaya tugasnya terlaksana dengan baik, seorang guru diharuskan mempunyai Softskill dan kemampuan dalam menguasai bidangnya keahliannya dalam menyampaikan pelajaran serta pelaksanaan evaluasi pembelajaran.

Salah satu cara yang dapat digunakan guru untuk membantu menghadirkan pembelajaran yang bermakna adalah dengan membuat media pembelajaran, khususnya media pembelajaran berbasis TIK. Konsep, informasi atau situasi baru yang ingin disampaikan oleh seorang guru akan menjadi lebih jelas apabila disampaikan menggunakan media pembelajaran berbasis TIK. Karena dengan menggunakan media pembelajaran berbasis TIK seorang guru dapat mengombinasikan beberapa unsur media, seperti media visual, audio, maupun audio visual. Sebagai contoh apabila seorang guru ingin menampilkan proses penguapan cukup dengan menampilkan gambar atau menampilkan video proses penguapan, guru tidak perlu menjelaskan panjang lebar dengan ceramah.

Media pembelajaran berbasis TIK memang dapat dikatakan cukup bermanfaat meringankan guru dalam kegiatan belajar mengajar, hanya saja fenomena yang muncul adalah guru menghadapi kesulitan dalam membuat media pembelajaran berbasis TIK. Hal tersebut dapat ditinjau dari beberapa penelitian diantaranya yang dilakukan oleh (Pramita, 2009), penelitiannya menunjukkan beberapa temuan, salah satunya yaitu, guru mengalami problematika dalam membuat media pembelajaran berbasis TIK. Tidak hanya itu, penelitian (Prakoso, 2015) dalam temuan penelitiannya menyebutkan bahwa tingkat kompetensi guru, kelas 1, 2, 4, dan 5 di SDN Se-Kecamatan Mojowarno Kabupaten Jombang dapat dikatakan dalam pengembangan media pembelajaran masih sangat rendah.

Maka dapat dirumusan focus penelitian ini yaitu; (1) Problematika yang dialami Guru IPS di SMP BSS mengembangkan Media Pembelajaran Berbasis TIK; (2) Yang menjadi permasalahan/problematika terjadi pada Guru IPS di SMP BSS; (3) Sikap Guru IPS di SMP BSS dalam mengatasi kesulitannya mengembangkan Media Pembelajaran basis TIK; (4) Upaya Guru IPS di SMP BSS Agar Permasalahan/problematika mengembangkan Media Pembelajaran Berbasis TIK teratasi. 


\section{Metode}

Metode penelitian yang digunakan yaitu metode kualitatif. Hal tersebut dikarenakan peneliti merasa cocok dengan sifat penelitian kualitatif yang fleksibel. Penelitian kualitatif sendiri memiliki beberapa pendekatan yang berbeda. Beberapa pendekatan tersebut adalah pendekatan dalam metode penelitian ini menggunakan pendekatan fenomenologi (Creswell, 2007).

Salah satu keunggulan penggunaan fenomenologi adalah deskripsi makna akan terbentuk berdasarkan esensi orang yang mengalami kejadian tersebut secara langsung, bila dikaitkan dengan penelitian ini maka orang tersebut adalah guru yang mengalami problematika dalam membuat media pembelajaran berbasis TIK. Sebagaimana (Gill, 2014) memaparkan yang pada intinya bahwa metode penelitian fenomenologi akan berusaha mencari deskripsi makna berdasarkan esensi makna orang yang mengalaminya langsung.

Mencari kebenaran yang hakiki memang suatu keniscayaan, karena setiap orang memiliki pandangan mengenai kebenarannya masing-masing. Jadi akan tidak etis apabila meneliti mengenai pengalaman hidup seseorang dengan membawa dogma, membawa kecurigaan, dan mendewakan teori daripada kenyataan. Sebagian besar figur pendiri fenomenologi mendukung untuk penolakan penggunaan dogma maupun apriori dalam penelitian fenomenologi, Seorang ahli fenomenologi bernama (Moran, 2002) memaparkan mengenai dukungan para figur pendiri fenomenologi untuk menolak semua bentuk dogma, kecurigaan, dan pendewaan teori daripada kenyataan memberikan gambaran bahwa mengembalikan sesuatu kepada hal yang konkret itu sangat penting. Jika ingin mencari tahu mengenai makna pengalaman hidup seseorang maka sudah sepantasnya mengembalikannya kepada si pemilik pengalaman.

Dalam penelitian ini kualitatif dan pendekatan fenomenologi peneliti harus langsung hadir untuk bertemu dengan informan, agar bisa terjalin komunikasi yang baik dengan informan, maka tidak boleh diwakilkan. Sebagaimana dikemukakan oleh (Sugiyono, 2012) Instrumen utama dalam penelitian kualitatif adalah peneliti, lebih lanjut (Rahmat, 2012) menegaskan dalam penelitian kualitatif, hubungan dengan informan adalah empati, akrab, memiliki kedudukan setaraf, dan dalam jangka waktu yang lama. Oleh sebab itu, peneliti harus bertatap muka langsung dengan informan agar memiliki empati dan akrab dengan informan.

Lokasi penelitian yaitu di SMP Brawijaya Smart School yang terletak di Jln. Cipayung No. 8 Malang. Untuk keperluan penelitian sendiri, kehadiran peneliti di SMP BSS dimulai 11 Januari sampai 11 Maret 2016. Sumber data yang digunakan yaitu sumber data primer dan sekunder. Sumber data primer dalam penelitian ini diperoleh dari wawancara mendalam kepada informan. Informan dalam konteks penelitian ini adalah si pemilik pengalaman, yaitu guru IPS yang ada di SMP BSS. Di SMP BSS ada tiga orang guru IPS, yaitu Ibu Yuli Astuti, Ibu Esti Lestari, dan Bapak Soedjiono. Kemudian Sumber data sekunder berasal dari analisis dokumen dan hasil observasi partisipatoris.

Setelah pengumpulan data maka hal yang harus dilakukan adalah melakukan analisis data. Pisau analisis yang digunakan dalam penelitian ini berasal dari bapak fenomenologi Edmund Husserl. Peneliti memilih pisau analisis Edmund Husserl karena menurut peneliti pisau analisis tersebut sesuai dengan konteks penelitian. Lebih lanjut (Gill, 2014) memaparkan langkah analisis peneliti fenomenologi sebagai berikut: cara analisis data fenomenologi yang diperkenalkan oleh Edmund Husserl. Agar dapat lebih mudah dipahami, berikut penjabaran 
mengenai cara analisis yang dipakai dalam penelitian ini; (1) Transkripsi. Tahapan transkripsi adalah tahap di mana peneliti menggambarkan sepenuhnya fenomena yang terjadi pada informan. Seluruh hasil rekaman wawancara mendalam yang diperoleh dari informan ditranskripkan. Hasil transkripsi tersebut berupa tulisan jalannya wawancara mendalam.

Tahapan kedua, Horizonalization. Hasil wawancara yang telah ditranskripkan akan dipakai dalam tahapan selanjutnya. Tahap tersebut adalah tahap Horizonalization, yaitu tahapan di mana peneliti mengarsipkan pernyataan penting yang memiliki relevansi dengan topik. Pada tahap ini, peneliti tidak disarankan melakukan penilaian (bracketing/epoche); artinya, unsur subjektivitasnya tidak tercampuri sebagai upaya merinci poin-poin penting sebagai data penelitian yang diperoleh dari hasil wawancara sebelumnya (Hasbiansyah, 2005).

Tahapan ketiga, Cluster of Meaning. Langkah selanjutnya peneliti mengklasifikasikan pernyataan sebelumnya dalam tema atau unit makna serta memilah pernyataan yang tumpang tindih. Pada tahap ini, dilakukan: (1) Textural description: menulis hal yang dialami mellalui deskripsi tentang pengalaman individu; (2) Structural description: menuliskan terjadinya fenomena.

Tahapan terakhir yaitu refleksi. Pada bagian ini peneliti melakukan refleksi antara hasil temuan penelitian dengan prinsip fenomenologi. Hal tersebut dilakukan untuk mengetahui esensi makna dari pengalaman dan problematika guru IPS dalam mengambangkan media pembelajaran berbasis TIK.

\section{Hasil dan Pembahasan}

Sebagaimana telah dipaparkan dalam metode penelitian, maka hasil dari penelitian ini merupakan hasil dari wawancara dengan pemilik pengalaman (informan). Segala informasi yang tertulis berdasarkan dari pernyataan pemilik pengalaman (informan). Pemilik pengalaman tersebut adalah guru IPS di SMP BSS, Ibu Yuli Puji Astuti, Ibu Esti Lestari, dan bapak Soedjiono.

\subsection{Kesadaran Akan Pentingnya Media Pembelajaran Berbasis TIK}

Berdasarkan dari hasil wawancara dengan informan ditemukan bahwa guru IPS menyadari akan pentingnya Media pembelajaran berbasis TIK. Mereka sadar akan pentingnya menggunakan media pembelajaran basis TIK. Menggunakan media pembelajaran basis TIK dapat menarik perhatian peserta didik karena pembelajaran lebih bervariatif. Banyak hal yang bisa ditampilkan oleh guru IPS. Selain itu, peserta didik juga dapat diajak untuk berpikir, karena peserta didik tidak hanya melihat, tapi juga bisa mendengar melalui media yang ditampilkan. Dengan demikian peserta didik dapat membayangkan, menggambarkan, dan menuliskan materi pembelajaran secara mandiri.

\subsection{Problematika dalam Mengembangkan Media Pembelajaran Berbasis TIK}

Problematika dalam pengoperasian software media pembelajaran berbasis TIK yang dihadapi oleh guru IPS di SMP BSS sangat beragam. Hal tersebut dikarenakan kemampuan para guru yang berbeda. Definisi kata "sulit" dalam konteks pengoperasian media pembelajaran berbasis TIK sangat relatif, tergantung pada setiap kemampuan individu. Ada yang mengalami kesulitan dalam memahami bahasa pemrograman, mencari bahan penunjang seperti wallpaper, gambar-gambar, membuat animasi, serta video dari internet. Pada intinya para guru 
IPS di SMP BSS mengalami kesulitan dalam mengoperasikan software dan mengikuti arus perkembangan teknologi.

Pertama adalah kesulitan dalam pengoperasian i media pembelajaran berbasis TIK. Berikut penjabarannya; (1) Kesulitan memahami bahasa pemrograman. Berbicara mengenai bahasa pemrograman, sebenarnya tidak semua media pembelajaran menggunakannya. Namun ada beberapa software media pembelajaran berbasis TIK yang memiliki bahasa pemrograman, jadi ketika ingin menampilkan sesuatu harus memasukkan rumus terlebih dahulu.; (2) Kesulitan dalam mencari bahan penunjang. Membuat media pembelajaran berbasis TIK tidak dapat dipisahkan dengan bahan penunjang lainnya, seperti gambar, animasi, musik, maupun video. Untuk dapat mengembangkan media pembelajaran basis TIK yang menarik maka guru mengombinasikan dengan beberapa bahan penunjang tersebut.

Selanjutnya problematika yang kedua yaitu mengikuti perkembangan teknologi. Perkembangan dari teknologi pada era ini sangat pesat dalam berbagai sektor. Begitu pula perkembangan teknologi dalam sektor pendidikan. Apabila seorang guru tidak dapat mengikuti perkembangan tersebut maka guru akan mengalami ketertinggalan dalam teknologi pembelajaran.

Menurut salah satu informan, yaitu ibu Esti. Perkembangan teknologi yang semakin canggih menuntut ibu Esti untuk semakin canggih pula. Tidak dapat dipungkiri, telah terjadi perkembangan yang pesat dalam teknologi pembelajaran. Software yang dapat dipakai untuk mengembangkan media pembelajaran berbasis TIK juga semakin beragam, namun ibu Esti menuturkan karena belum bisa mengimbangi perkembangan teknologi ibu Esti hanya mampu sebatas menguasai media pembelajaran powerpoint.

\subsection{Penyebab Munculnya Problematika Mengembangkan Media Pembelajaran Berbasis TIK}

Guru IPS di SMP BSS mengembangkan media pembelajaran menghadapi beberapa problematika. Antara lain problematika tersebut adalah kesulitan dalam pengoperasian software media pembelajaran, dan juga kesulitan dalam mengikuti laju perkembangan teknologi. Berdasarkan apa yang telah diutarakan oleh guru IPS yang ada di SMP BSS, problematika tersebut muncul karena beberapa hal yakni kerumitan pengoperasian software media pembelajaran, faktor kurangnya pembiasaan dalam menggunakan/megoperasikan, usia, waktu, tidak adanya pendampingan, perbedaan generasi dan juga banyaknya tugas tambahan yang dimiliki oleh guru IPS di SMP BSS.

\subsection{Sikap dan Harapan Guru IPS dalam Menghadapi Problematika pengembangan Media Pembelajaran Berbasis TIK}

Berbagai problematika yang dihadapi oleh guru IPS dalam mengembangkan media pembelajaran berbasis TIK sangat beragam. Mulai dari masalah pengoperasian software sampai dengan kesulitan mengikuti perkembangan teknologi. Tidak hanya problematika yang dihadapi saja yang beragam, namun juga dengan penyebab munculnya problematikanya.

Beberapa penyebab munculnya problematika tersebut antara lain, kurangnya pembiasaan dalam pengoperasian, factor usia, tidak adanya pendampingan keterampilan, perbedaan yang dipelajari antar generasi, overload tugas tambahan guru, dan juga kurangnya 
kesempatan dalam pembagian waktu untuk belajar. Dari berbagai hal tersebut guru IPS yang ada di SMP BSS tidak diam saja, mereka melakukan sesuatu untuk menyikapi hal tersebut.

Berbagai macam sikap diambil oleh para guru IPS di SMP BSS antara lain, mengerjakan semua tugas tambahan yang diberikan oleh sekolah, melakukan manajemen waktu, dan juga semangat untuk terus belajar. Selain melakukan hal tersebut, mereka juga memiliki harapan agar institusi melakukan upaya-upaya untuk menghadapi problematika yang mereka hadapi. Upaya yang diharapkan yaitu seperti memberikan program workshop dan pelatihan pembuatan media pembelajaran, tidak ada tugas tambahan, melengkapi fasilitas pendukung media pembelajaran berbasis TIK, dan memberikan program pendampingan pembuatan media pembelajaran berbasis TIK secara intensif.

\section{Simpulan}

Berdasarkan hasil dari temuan penelitian dapat dipahami beberapa hal. Pertama, Guru IPS di SMP BSS sadar akan pentingnya media pembelajaran berbasis TIK. Kedua,dalam membuat media pembelajaran berbasis TIK mereka mengalami kesulitan dalam pengoperasian software dan dalam mengikuti perkembangan teknologi yang selalu ada pembaharuan. Ketiga, permasalahan/problematika tersebut muncul disebabkan oleh berbagai faktor, factor usia, tidak adanya pendampingan keterampilan, perbedaan yang dipelajari antar generasi, overload tugas tambahan guru, dan juga kurangnya kesempatan dalam pembagian waktu untuk belajar. Keempat, banyaknya problematika yang mereka hadapi tidak hanya membuat mereka pasrah, namun mereka melakukan beberapa cara untuk menyikapi problematika mengembangkan media pembelajaran berbasis TIK adalah dengan mengerjakan tugas tambahan yang diberikan, melakukan manajemen waktu, dan juga menjaga semangat belajar.

Tidak hanya empat hal tersebut, yang terakhir mereka juga mengharapkan adanya dukungan dan upaya dari instansi terkait agar problematika yang mereka hadapi dapat teratasi. Mereka mengharapkan pihak sekolah segera melengkapi fasilitas penunjang pembelajaran berbasis TIK di kelas yang belum didukung dengan fasilitas tersebut, tidak adanya tugas tambahan, diadakan pelatihan atau worskshop seperti yang mereka harapkan, dan yang terakhir adalah diadakannya pendampingan pembuatan media pembelajaran berbasis TIK secara intensif.

Beberapa saran terkait hasil penelitian: (1) Bagi pemerintah, sebaiknya memberikan perhatian lebih kepada guru tentang pemanfaatan media pembelajaran, dengan cara memberikan pendampingan secara intensif kepada guru dalam memanfaatkan teknologi informasi dan komunikasi; (2) Bagi Universitas Negeri Malang sebaiknya memaksimalkan kurikulum pengembangan media pembelajaran, khususnya media pembelajaran berbasis TIK. Agar nantinya para calon guru yang lulus dari UM dapat menjadi penggagas kemajuan teknologi pembelajaran Indonesia; (3) Bagi sekolah sebaiknya membuat pendampingan secara intensif mengenai pemanfaatan media pembelajaran berbasis TIK kepada para guru di SMP BSS; (4) Bagi pemerhati pendidikan sebaiknya membuat gerakan sosial yang berfokus kepada teknologi pembelajaran. Salah satu gerakan sosial yang dapat dipertimbangkan adalah dengan membuat gerakan sosial Sekolah Melek Teknologi; (5) Bagi guru sebaiknya melakukan refleksi mengenai kemampuan dalam penguasaan teknologi pembelajaran.

Poin satu sampai lima merupakan saran secara praktis. Sedangkan saran secara teoretis ditunjukkan untuk peneliti yang ingin meneliti dengan tema yang sama. Peneliti menyarankan 
untuk meninjau dari sudut pandang yang berbeda, bisa ditinjau dari pemerintah, ditinjau dari instansi pendidikan kampus. Semakin bertambahnya penelitian mengenai problematika guru IPS dalam membuat media pembelajaran berbasis TIK dapat menambah khazanah ilmu pengetahuan dalam bidang Ilmu Pengetahuan Sosial serta memberikan pengaruh positif bagi kemajuan IPS.

\section{Daftar Rujukan}

Brown, A. P. (2010). Qualitative method and compromise in applied social research. Qualitaive Research. Retrieved from (Online), 10 (2): 229-248, (http://qrj.sagepub.com/content/10/2/229.full.pdf), diakses 26 November 2015

Creswell, J. W. ( 2007). Qualitatif Inquiry \& Research Design, Chosing Among Five Approaches. London: Sage Publications.

Gill, M. J. (2014). The Possibilities of Phenomenology for Organizational Research. Organizational Research Methods, (Online), 17 (2): 118-137, (http://orm.sagepub.com/content/17/2/118.full.pdf), diakses 26 November 2015.

Hasbiansyah, O. (2005). Pendekatan Fenomenologi: Pengantar dalam Praktik Penelitian Ilmu Sosial dan Komunikasi. Mediator, (Online), 9 (01): 163-180,(http://download.portalgaruda.org/article.php?article=117304\&val=5336), diakses 1 oktober 2015 .

Majid, A. (2014). Pembelajaran Tematik Terpadu. Bandung: PT Remaja Rosdakarya.

Moran, D. (2002). Introduction to Phenomenology. London: Taylor \& Francis E-library.

Peraturan Menteri Pendidikan Nasional No. 16 Tahun 2007 tentang Standar Kualifikasi Akademik dan Kompetensi Guru. Menteri Pendidikan Nasional. (n.d.). Retrieved from (Online), (http://portal.mahkamahkonstitusi.go.id), diakses 8 Desember 2015.

Peraturan Pemerintahan Republik Indonesia No. 74 Tahun 2008 tentang Guru. (n.d.). Retrieved from (Online), (http://direktori.madrasah.kemenag.go.id/media/files/PP74TH2008.pdf), diakses 16 Desember 2015.

Prakoso, A. B. (2015). Tingkat Kompetensi Guru dalam Pengembangan Media Pembelajaran di SDN SeKecamatan Mojowarno Kabupaten Jombang. Malang: Skripsi tidak diterbitkan. Malang: Program Studi Pendidikan Guru Sekolah Dasar Universitas Negeri Malang.

Pramita, R. (2009). Problematika guru dalam membuat media pembelajaran (studi kasus SMA Negeri di kota Malang). Malang: Skripsi tidak diterbitkan. Malang: Program Studi Pendidikan Pancasila dan Kewarganegaraan Unversitas Negeri Malang.

Rahmat, P. S. (2012). Penelitian Kualitatif. Jurnal penelitian kualitatif, (Online), (http://yusuf.staff.ub.ac.id/files/2012/11/Jurnal-Penelitian-Kualitatif.pdf), diakses 1 oktober 2015.

Sugiyono. (2012). Metode Penelitian Pendidikan. Bandung: Alfabeta. 